\title{
Editorial \\ Development of 'synthetic lethal' strategies to target BRCA1-deficient breast cancer
}

\author{
Max S Wicha
}

University of Michigan Comprehensive Cancer Center, 1500 E. Medical Center Drive, 6302 CC Ann Arbor, MI 48109-5942, USA

Corresponding author: Max S Wicha, mwicha@umich.edu

Published: 23 September 2009

Breast Cancer Research 2009, 11:108 (doi:10.1186/bcr2362)

This article is online at http://breast-cancer-research.com/content/11/5/108

(c) 2009 BioMed Central Ltd

See related research by Puppe et al., http://breast-cancer-research.com/content/11/4/R63

\begin{abstract}
Recent clinical trials demonstrating the efficacy of poly(ADPribose) polymerase (PARP) inhibitors for the treatment of BRCA1deficient breast cancer have provided support for the 'synthetic lethal' concept of targeted cancer therapeutics. A new study provides further preclinical validation of this concept by demonstrating that BRCA1-deficient mouse mammary tumor cells are selectively sensitive to an inhibitor of the polycomb gene EZH2. The development of polycomb gene inhibitors may provide a novel approach to selectively exploit the molecular alterations in BRCA1deficient breast tumors.
\end{abstract}

In the previous issue of Breast Cancer Research, Puppe and colleagues [1] describe a novel approach to selectively target BRCA1-deficient breast tumors. One of the most exciting recent developments in clinical oncology has been the demonstration of significant clinical efficacy of inhibitors of poly(ADP-ribose) polymerase (PARP) in BRCA1-deficient breast tumors [2]. The development of PARP inhibitors was based on the concept of 'synthetic lethality', which posits that a compound targeting a particular pathway may be selectively 'lethal' to cells harboring a mutation in a complementary pathway. It was demonstrated, consistent with such a concept, that cells lacking BRCA1 repair function were 1,000-fold more sensitive to PARP inhibition than cells with intact DNA repair pathways [3,4]. Puppe and colleagues [1] use a mouse model of BRCA1-deficient breast tumors to identify $E Z H 2$ as another 'drugable' synthetic lethal target. They used expression profiling to identify EZH2 as a gene that was significantly overexpressed in BRCA1-deficient mouse mammary tumors as well as in breast tumors from women with BRCA1 germline mutations. Importantly, cells derived from BRCA1-deficient mouse mammary tumors were 20-fold more sensitive to the small-molecule EZH2 inhibitor (DZNep) than were cells derived from mouse mammary tumors with normal BRCA1 expression. The specificity of this effect was demonstrated by similar 'synthetic lethality' of BRCA1-deficient cells to EZH2 knockdown by a short interfering RNA. Furthermore, this effect was reversed upon restoration of BRCA1 expression.

\section{EZH2 function}

$E Z H 2$ is a subunit of the large 'polycomb repressor complex 2', which initiates gene silencing by trimethylating lysine 27 in histone H3 (H3-K27 ME3). PRC1 complex genes, including $B m i-1$, are then recruited to these marked histone sites, where they mediate repression of gene expression [5]. EZH2 has been reported to be expressed mainly in human basal carcinomas, where this expression is associated with high proliferation and poor patient outcome [6,7]. EZH2 has been reported to regulate cell proliferation through interaction with key growth-regulating pathways, including members of the $\mathrm{Rb}$ family as well as Ink4A and Ink4B $[5,8]$. Although PRC2 and PRC1 polycomb genes function in a 'linear fashion' in normal development, it has been suggested that their overexpression may have different functional consequences for breast tumorigenesis [9]. Nevertheless, both EZH2 and $B m i-1$ have been shown to play important roles in regulating the self-renewal and differentiation of normal stem cells. This occurs through modulation of stem cell self-renewal and inhibition of genes promoting cellular differentiation [8].

\section{BRCA1 and breast development}

Recent studies have demonstrated that, in addition to its wellknown role in DNA repair, BRCA1 plays an important role in breast development. Liu and colleagues [10] demonstrated that BRCA1 regulates the differentiation of estrogen receptor (ER)-negative breast stem cells into ER-positive luminal progenitors. Recently, Lim and colleagues [11] reported that breast tissue from BRCA1 mutation carriers contains expanded luminal progenitor cells, suggesting a broader role

$E R=$ estrogen receptor; PARP $=$ poly (ADP-ribose) polymerase. 
for BRCA1 in the regulation of breast, stem, and progenitor cells. Together, these studies suggest that the loss of BRCA1 function may result in the expansion of the breast stem and progenitor cell populations, providing targets for further carcinogenic events. Although the exact relationship between BRCA1 and EZH2 is not yet clear, Gonzalez and colleagues [12] recently demonstrated that BRCA1 is required for $E Z H 2$ to mediate proliferation in breast cancer cell lines. Downregulation of EZH2 decreased the growth of ER-negative breast cancer cells, an effect reversed by BRCA1 knockdown.

\section{Targeting of breast cancer 'stem cells'}

Recent studies have suggested that many tumors, including those of the breast, may be initiated and maintained by a cellular population that displays 'stem cell' properties. These properties include self-renewal, which drives tumorigenesis, and differentiation, which generates the non-self-renewing population comprising the tumor bulk. Breast cancer stem cells may mediate metastasis and contribute to treatment resistance [13]. Although EZH2 and BRCA1 play a role in the biology of normal stem cells, the role of these genes in the regulation of breast cancer stem cells is not well defined. It will be most interesting to determine whether EZH2 inhibition is able to target 'breast cancer stem cells' in addition to bulk cell populations in BRCA1-deficient tumors. The demonstration by Puppe and colleagues that DZNep reduced tumorsphere formation, a property of stem cells, is consistent with this possibility. However, the systemic toxicity of this compound precluded its use in vivo, making an assessment of its effect on 'tumor initiating' capacity difficult. An additional important unanswered question is whether the approach described by Puppe and colleagues will also show utility in the therapy of sporadic basal breast tumors, many of which have decreased BRCA1 activity as a result of gene methylation [14]. EZH2 inhibition could potentially be combined with PARP inhibition as a 'double synthetic lethal' strategy for the treatment of this category of breast tumors. In any case, this study reinforces the feasibility of developing 'synthetic lethal' strategies aimed at selectively targeting genetically altered cancer cell populations. Hopefully, these strategies will result in the development of therapies that are more effective and less toxic.

\section{Competing interests}

MSW has financial holdings in and is a scientific advisor for OncoMed Pharmaceuticals, Inc. (Redwood City, CA, USA).

\section{References}

1. Puppe J, Drost R, Liu X, Joosse SA, Evers B, Cornelissen-Steijger $P$, Nederlof $P, Y u$, Jonkers J, van Lohuizen M, Pietersen AM: BRCA1-deficient mammary tumor cells are dependent on EZH2 expression and sensitive to polycomb repressive complex 2-inhibitor 3-deazaneplanocin A. Breast Cancer Res 2009, 11:R63.

2. Fong PC, Boss DS, Yap TA, Tutt A, Wu P, Mergui-Roelvink $M$, Mortimer P, Swaisland H, Lau A, O'Connor MJ, Ashworth A, Carmichael J, Kaye SB, Schellens JH, de Bono JS: Inhibition of
poly(ADP-ribose) polymerase in tumors from BRCA mutation carriers. N Engl J Med 2009, 361:123-134.

3. Farmer H, McCabe N, Lord CJ, Tutt AN, Johnson DA, Richardson TB, Santarosa M, Dillon KJ, Hickson I, Knights C, Martin NM, Jackson SP, Smith GC, Ashworth A: Targeting the DNA repair defect in BRCA mutant cells as a therapeutic strategy. Nature 2005, 434:917-921.

4. Bryant HE, Schultz N, Thomas HD, Parker KM, Flower D, Lopez E, Kyle S, Meuth M, Curtin NJ, Helleday T: Specific killing of BRCA2-deficient tumours with inhibitors of poly(ADP-ribose) polymerase. Nature 2005, 434:913-917.

5. Tonini T, D'Andrilli G, Fucito A, Gaspa L, Bagella L: Importance of Ezh2 polycomb protein in tumorigenesis process interfering with the pathway of growth suppressive key elements. J Cell Physiol 2008, 214:295-300.

6. Kleer CG, Cao Q, Varambally S, Shen R, Ota I, Tomlins SA, Ghosh D, Sewalt RG, Otte AP, Hayes DF, Sabel MS, Livant D, Weiss SJ, Rubin MA, Chinnaiyan AM: EZH2 is a marker of aggressive breast cancer and promotes neoplastic transformation of breast epithelial cells. Proc Natl Acad Sci U S A 2003, 100:11606-11611.

7. Arnes JB, Collett K, Akslen LA: Independent prognostic value of the basal-like phenotype of breast cancer and associations with EGFR and candidate stem cell marker BMI-1. Histopatho/ogy 2008, 52:370-380.

8. Ezhkova E, Pasolli HA, Parker JS, Stokes N, Su IH, Hannon G, Tarakhovsky A, Fuchs E: Ezh2 orchestrates gene expression for the stepwise differentiation of tissue-specific stem cells. Cell 2009, 136:1122-1135.

9. Pietersen AM, Horlings HM, Hauptmann M, Langerød A, Ajouaou A, Cornelissen-Steijger P, Wessels LF, Jonkers J, van de Vijver $\mathrm{MJ}$, van Lohuizen M: EZH2 and BMI1 inversely correlate with prognosis and TP53 mutation in breast cancer. Breast Cancer Res 2009, 10:R109.

10. Liu S, Ginestier C, Charafe-Jauffret E, Foco H, Kleer CG, Merajver SD, Dontu G, Wicha MS: BRCA1 regulates human mammary stem/progenitor cell fate. Proc Natl Acad Sci U S A 2008, 105: 1680-1685.

11. Lim E, Vaillant F, Wu D, Forrest NC, Pal B, Hart AH, Asselin-Labat ML, Gyorki DE, Ward T, Partanen A, Feleppa F, Huschtscha LI, Thorne HJ; kConFab, Fox SB, Yan M, French JD, Brown MA, Smyth GK, Visvader JE, Lindeman GJ: Aberrant luminal progenitors as the candidate target population for basal tumor development in BRCA1 mutation carriers. Nat Med 2009, 15: 907-913.

12. Gonzalez ME, Li X, Toy K, DuPrie M, Ventura AC, Banerjee M, Ljungman M, Merajver SD, Kleer CG: Downregulation of EZH2 decreases growth of estrogen receptor-negative invasive breast carcinoma and requires BRCA1. Oncogene 2009, 28: 843-853.

13. Kakarala M, Wicha MS: Implications of the cancer stem-cell hypothesis for breast cancer prevention and therapy. J Clin Oncol 2008, 26:2813-2820.

14. Turner N, Tutt A, Ashworth A: Hallmarks of 'BRCAness' in sporadic cancers. Nat Rev Cancer 2004, 4:814-819. 